\title{
PENERAPAN METODE DINSAR UNTUK ANALISA DEFORMASI AKIBAT GEMPA BUMI DENGAN VALIDASI DATA GPS SUGAR (STUDI KASUS: KEPULAUAN MENTAWAI, SUMATERA BARAT)
}

\author{
Ana Rizka Sari ${ }^{1}$, Hepi Hapsari $\mathrm{H}^{1}$, Agustan ${ }^{2}$ \\ ${ }^{1}$ Teknik Geomatika, FTSP, Institut Teknologi Sepuluh Nopember Surabaya (ITS) \\ Jl. Arief Rahman Hakim, Surabaya 60111 Indonesia \\ Email : hepihapsari@gmail.com \\ ${ }^{2}$ Pusat Teknologi Inventarisasi Sumber Daya Alam (PTISDA), Badan Pengkajian dan Penerapan Teknologi (BPPT) \\ Jl. MH. Thamrin 8, Jakarta 10340 Indonesia
}

\begin{abstract}
Abstrak
InSAR merupakan alat yang kuat untuk pengukuran deformasi di permukaan tanah dengan ketelitian subsentimeter. InSAR menggabungkan dua buah citra SAR untuk menghasilkan citra interferogram. Citra interferogram inilah yang digunakan untuk melakukan pemantauan pergerakan tanah. Mentawai adalah salah satu wilayah di Indonesia yang terletak di cincin api dunia. Berdasarkan struktur tektonik, gempa Mentawai yang terjadi pada tanggal 25 Oktober 2010 terjadi sebagai akibat dari lempeng Indo-Australia bergerak ke arah utaratimur laut dengan lempeng Sunda dengan kecepatan 57-69 mm / tahun.
\end{abstract}

Penelitian deformasi di daerah rawan gempa menggunakan sepasang ALOS PALSAR pada tanggal 29 September 2010 dan 14 November 2010. Sebagai model elevasi eksternal digunakan DEM SRTM3 90 m. Metode yang digunakan adalah two-pass differential interferometry synthetic aperture radar (DInSAR).

Hasil pengolahan metode DInSAR menunjukkan pergeseran antara $-20 \mathrm{~cm}$ sampai $20 \mathrm{~cm}$. Berdasarkan hasil pengolahan SAR untuk mengetahui akurasi deformasi dilakukan validasi dengan data GPS kontinyu SuGAr (SuGAr Network). SuGAr Network adalah jaringan stasiun GPS di sepanjang batas lempeng Sumatera. SuGAr Network yang digunakan untuk validasi data SAR adalah stasiun MKMK, BSAT, PRKB dan BSAT. Pergeseran di setiap stasiun GPS menuju zona subduksi trench Sumatera dengan nilai pergeseran yang relatif besar, yaitu 7,268 cm, $4,352 \mathrm{~cm}$ dan 5,576 cm di stasiun pengamatan GPS BSAT, PRKB dan SLBU. Hasil metode DInSAR dengan data GPS kontinyu SuGAr memiliki residu rata-rata $0,947 \mathrm{~cm}$. Berdasarkan hasil pengolahan data GPS, dapat disimpulkan terjadi penurunan tanah di setiap stasiun GPS dengan arah pergerakan ke barat daya.

Kata kunci : DInSAR, Gempa Bumi, Deformasi, Jaringan SuGAr

\section{PENDAHULUAN}

\section{Latar Belakang}

Perkembangan teknologi telah memunculkan beragam cara untuk melakukan pemantauan dan pemetaan terhadap aktifitas pergerakan bumi. Aktifitas pergerakan bumi erat kaitannya dengan fenomena deformasi. Salah satu teknologi yang dikembangkan untuk pemantauan deformasi ialah menggunakan teknologi Interferometry Synthetic Aperture Radar (InSAR). InSAR merupakan alat yang kuat untuk pengukuran deformasi di permukaan tanah dengan ketelitian sub-sentimeter.

Indonesia merupakan daerah rawan gempa bumi karena dilalui oleh jalur pertemuan tiga lempeng tektonik, yaitu: lempeng Indo-
Australia, lempeng Eurasia, dan lempeng Pasifik. Jalur pertemuan lempeng berada di laut sehingga apabila terjadi gempa bumi besar dengan kedalaman dangkal maka akan berpotensi menimbulkan tsunami sehingga Indonesia juga rawan tsunami.

Mentawai merupakan salah satu wilayah di Indonesia yang terletak dalam ring of fire dunia. Berdasarkan tatanan tektoniknya, gempa Mentawai yang terjadi pada tanggal 25 Oktober 2010 terjadi akibat interaksi antara batas lempeng subduksi Indo-Australia dan subduksi lokal Sunda. Berdasarkan solusi mekanisme lokal dan kedalamannya, gempa ini memiliki mekanisme sesar naik dan terjadi di sepanjang plate interface (Yudhicara, 2010). 
Gempa bumi sangat berpengaruh pada perubahan dan bentuk tanah yang biasanya disebut deformasi. Hal ini dikarenakan semua proses yang terjadi berasosiasi dengan pergerakan lempeng-lempeng dunia.

Deformasi sangat berhubungan erat dengan gempa bumi yakni akibat cosesismic dan postseismic. Gempa bumi biasanya akan menyebabkan kerak bumi disekitarnya terdeformasi baik dalam arah vertikal dan hirosontal. Banyak observasi telah dilakukan untuk mengetahui deformasi seperti observasi langsung menggunakan teknologi GPS dan observasi tak langsung menggunakan citra satelit resolusi tinggi.

\section{Perumusan Masalah}

Perumusan masalah dalam kajian ini antara lain:

1. Bagaimana menerapkan metode DInSAR untuk mengetahui deformasi cosesismic dan post-seismic?

2. Bagaimana mengetahui pergerakan tanah (subsidence atau uplift) akibat gempa bumi di Kepulauan Mentawai?

3. Berapa besar deformasi berdasarkan Line of Sight (LOS) menggunakan metode DInSAR?

4. Bagaimana memvalidasi hasil deformasi yang didapat dengan metode DInSAR menggunakan perbandingan hasil pengolahan data GPS dalam Sumatran GPS Array (SuGAr) Network?

\section{METODOLOGI PENELITIAN}

\section{Lokasi Penelitian}

Lokasi penelitian ini adalah gempa bumi yang terjadi di Kepulauan Mentawai, Sumatera Barat pada tanggal 25 Oktober 2010. Posisi geografis terletak pada $0^{\circ} 55^{\prime} 00^{\prime \prime}-3^{\circ} 21^{\prime} 00^{\prime \prime}$ LS dan $98^{\circ} 35^{\prime} 00^{\prime \prime}$ - $100^{\circ} 32^{\prime} 00^{\prime \prime}$ BT yang berada di jalur lempeng tektonik sehingga sering terjadi gempa tektonik.

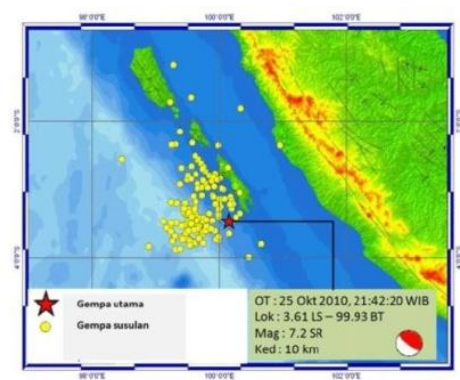

Gambar 1. Lokasi Penelitian

\section{Data dan Peralatan}

Data

Data yang digunakan dalam penelitian ini adalah :

a. Citra satelit ALOS PALSAR Level 1.0 Fine Beam Dual Polarization (FBD) tanggal 29 September 2010 dan 14 November 2010

b. DEM SRTM 90 meter

c. Data GPS dalam SuGAr Network diambil dari tanggal 22-28 Oktober 2010

d. Data titik episentrum gempa bumi Kepulauan Mentawai, Sumatera Barat

e. Data zona subduksi dan patahan

\section{Peralatan}

Peralatan yang digunakan dalam penelitian ini adalah Personal Computer (PC) / Notebook, Microsoft Office Word, OS Ubuntu 12.04 LTS, GMT, GMTSAR, Toopcon tools, Matlab 7.7.0

\section{Tahapan Penelitian}

Diagram Alir proses Pengolahan Data pada penelitian ini ditunjukkan oleh Gambar 2. 


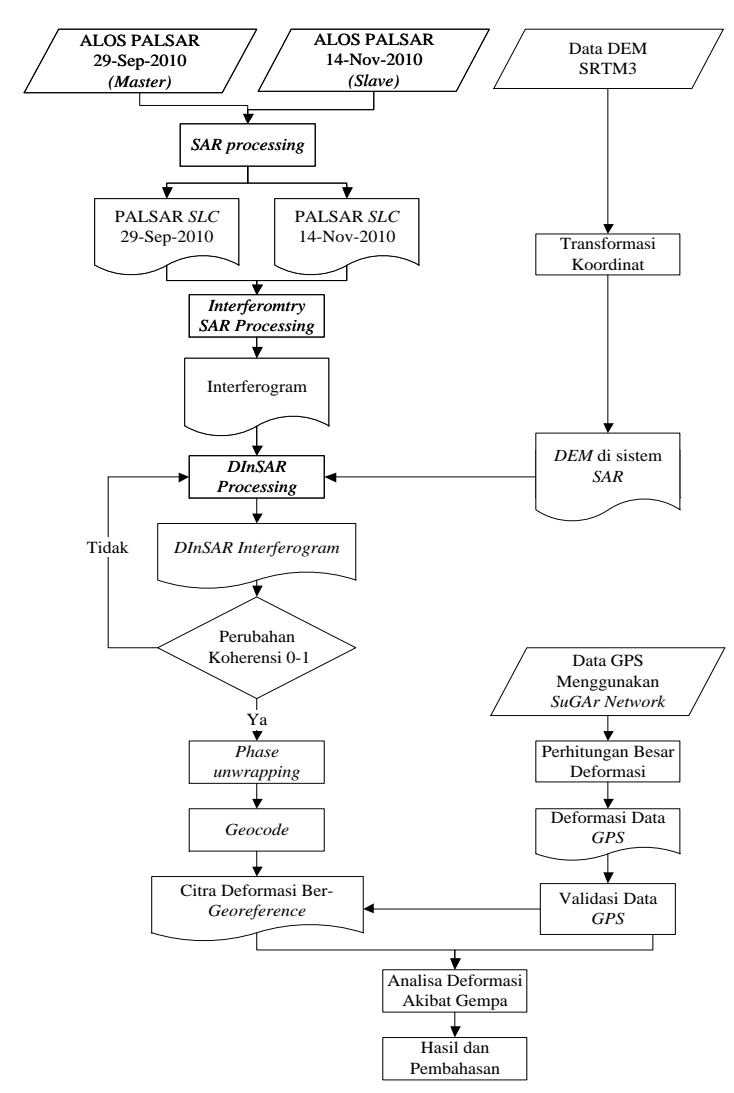

Gambar 2. Diagram Alir Tahapan Pengolahan Data

\section{HASIL DAN ANALISA}

\section{Hasil}

1. Koherensi Citra SAR

Untuk melihat tingkat koherensi citra secara kualitatif dapat dilihat dari citra koherensi.

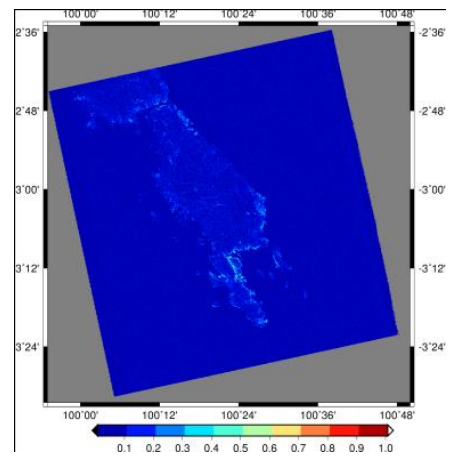

Gambar 3. Interferogram Citra Koherensi

Pada Gambar 3, scalebar dengan objek water bodies di sekeliling Kepulauan Mentawai akan menunjukkan warna biru dengan nilai koherensi lebih kecil dari 0,1 sampai mendekati 0 . Hal ini disebabkan karena water bodies bergerak terus menerus secara konstan. Akibatnya rona warna citra koherensi yang didapat menuju rona gelap (scalebar bergerak ke arah kiri). Pada daratan memiliki koherensi antara 0,2-0,4. Rendahnya koherensi ini karena sebagian besar area studi kasus memiliki kerapatan vegetasi yang tinggi. Kerapatan vegetasi ini akan mempengaruhi nilai koherensi citra karena pergerakan dan perubahan vegetasi akan berpengaruh pada pantulan backscatter-nya. Hasil citra koherensi Kepulauan Mentawai rendah juga disebabkan oleh panjang baseline antar dua pengamatan yang besar. Apabila citra koherensi memiliki tingkat koherensi yang tinggi, maka scalebar pada Gambar 3 di atas akan menuju warna terang (scalebar bergerak ke arah kanan). Rendahnya nilai koherensi ini menyebabkan banyaknya piksel yang kosong setelah citra melalui proses unwrap.

\section{Besar Deformasi Setelah Unwrap Processing} Proses unwrapping menghitung perbedaan phase pada interferogram dari satu titik ke titik berikutnya dan meng-generalisasinya menjadi perbedaan phase yang lebih halus. Apabila area relatif datar (tanpa atau perbedaan phase jump kecil antar titik), proses unwrap mudah untuk dilakukan. Akan tetapi jika area studi memiliki bentuk topografi yang beragam (perbedaan phase jump besar) maka proses unwrap akan sangat sulit dilakukan. Pada Gambar 4 menunjukkan hasil unwrap besar displacement Kepulauan Mentawai selama tahapan coseismic dan post-seismic.

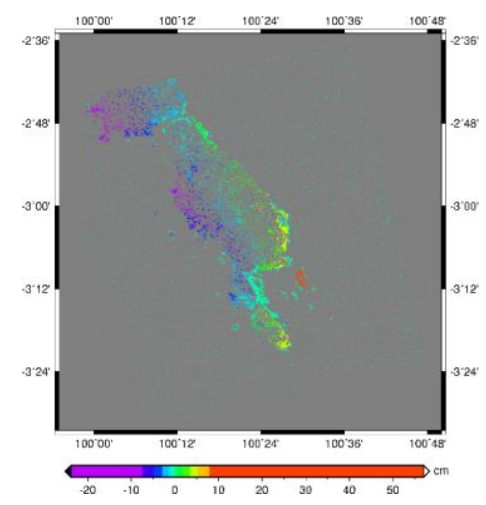

\section{Gambar 4. Hasil Citra Unwrap dalam Metrik}

Pada scalebar, warna violete pada citra hasil unwrap menunjukkan terjadi penurunan (sudsidence) pada area studi kasus. Area tidak mengalami atau hampir tidak mengalami subsidence atau uplift yang ditunjukkan dengan warna skyblue. Apabila rona warna bergerak dari skyblue ke orange (semakin ke kanan) 
menunjukkan kenaikan muka tanah (uplift).

Untuk melihat sebaran deformasi di Kepulauan Mentawai berdasarkan hasil unwrap dilakukan cross section atau irisan melintang pada areaarea yang mengalami subsidence atau uplift. Pada Gambar 5 menunjukkan kecendurungan area studi kasus mengalami subsidence.

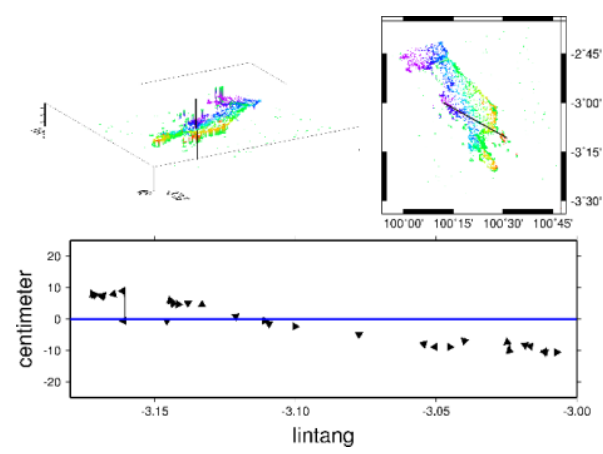

Gambar 5. Displacement Hasil Unwrap

3. Besar Deformasi Hasil Pengolahan Data GPS SuGAr Network adalah jaringan stasiun GPS di sepanjang batas lempeng Sumatera. Hasil pengolahan data GPS dalam penelitian ini bersifat lokal sehingga besar deformasi pada area studi kasus relatif terhadap letak stasiun GPS yang digunakan sebagai base yakni stasiun GPS MKMK yang terletak di provinsi Sumatera Barat, sedangkan yang digunakan sebagai rover adalah stasiun BSAT, PRKB, SLBU yang terletak di Kepulauan Mentawai. Besarnya deformasi dalam arah northing, easting dan elevation yang dilambangkan dengan $d n$, de dan $d H$. Nilai pergeseran ini diperoleh dari tiga hari data pengamatan sebelum gempa dan tiga hari data pengamatan setelah gempa terjadi.

Pada saat menjelang gempa (22-24 Oktober 2010) tidak terjadi besar deformasi yang signifikan yang ditunjukkan besar pergeseran rata-rata gempa $\mathrm{H}-3$ di setiap stasiun GPS, akan tetapi besar deformasi selepas gempa (26-28 Oktober 2010), pergeseran rata-rata $(\mathrm{H}+3)$ relatif besar. Stasiun GPS yang mengalami pergeseran rata-rata horizontal dan vertikal terbesar adalah stasiun GPS BSAT, sedangkan yang terkecil adalah stasiun GPS PRKB. Detil dari pola deformasi 3 hari sebelum dan 3 hari setelah gempa ditampilkan pada grafik.

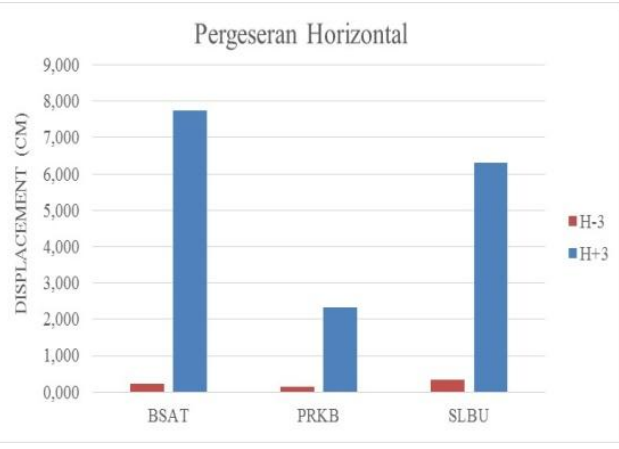

(a)

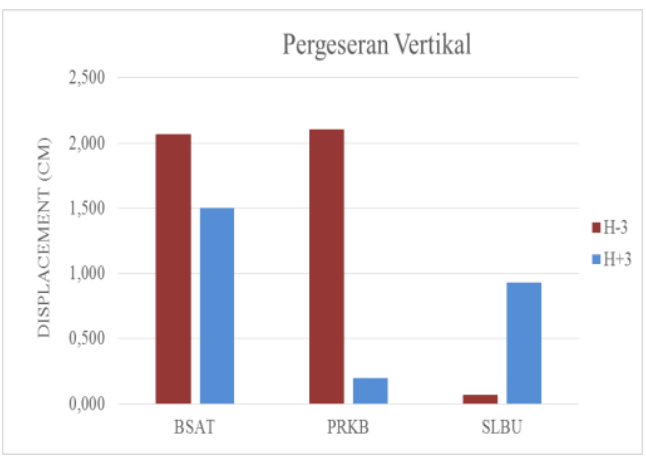

(b)

Gambar 6. Pergeseran (a) Horizontal dan (b) Vertikal Tiga Hari Sebelum dan Setelah Gempa

Pada Gambar 7. (a) dan (b) ditampilkan visualisasi vektor pergeseran data terhadap arah horizontal dan vertikal. Dapat diamati pada Gambar 7 (a) bahwa pergerakan horizontal stasiun SuGAr menuju arah barat daya menuju ke arah trench zona subduksi Sumatra. Pergeseran yang diamati juga dalam lingkup vertikal (naik atau turun) yang ditunjukkan pada Gambar 7 (b), dapat dilihat bahwa pergerakan stasiun SuGAr menunjukkan arah bawah/turun (bernilai negatif).

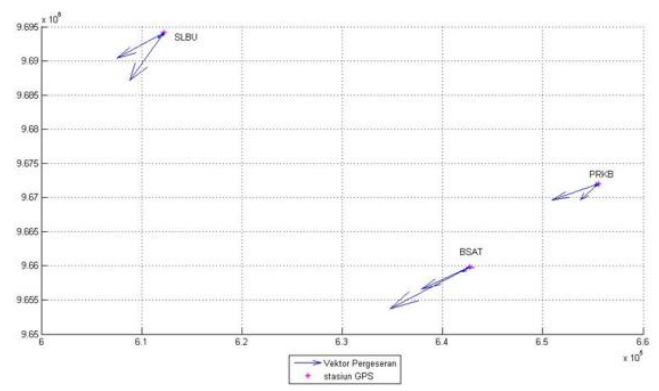

(a) 


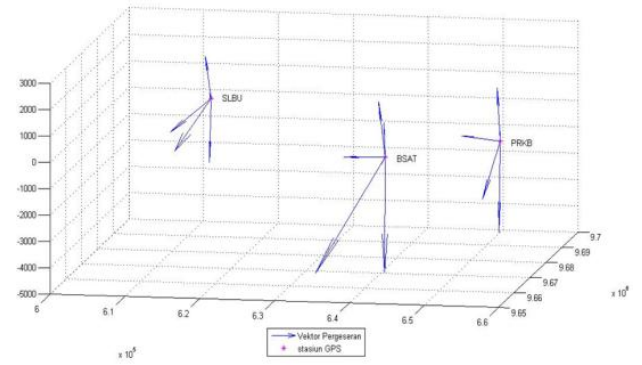

(b)

Gambar 7. Pergerakan (a)Horizontal dan (b)Vertikal

Titik-titik pengamatan GPS terletak pada aktivitas subduksi lempeng Indo-Australia terhadap lempeng Eurasia yang mengalami pergerakan setiap tahunnya. Lempeng IndoAustralia memiliki pergerakan relatif ke arah timur-timur laut dengan kecepatan \pm 7,7 $\mathrm{cm} /$ tahun. Oleh karena itu, vektor pergeseran toposentrik hasil pengolahan data GPS masih dipengaruhi oleh pergerakan lempeng tersebut. (Mubyarto, 2008)

\section{Analisa Kondisi Geologi}

Berdasarkan tatanan tektonik regional, Sumatera dan sekitarnya merupakan suatu tepian aktif di Sundaland yang memiliki pergerakan relatif ke arah timur-timur laut dengan kecepatan $7,7 \mathrm{~cm} /$ tahun.

Menurut hasil penelitian Kementerian Energi dan Sumber Daya Mineral RI, Kondisi Geologi Pesisir Selatan dan sekitarnya tersusun oleh aluvium dan batuan vulkanik berumur Kuarter serta batuan sedimen berumur Tersier. Aluvium dan batuan vulkanik Kuarter mempunyai sifat lepas, urai, belum terkompaksi dengan baik. Batuan sedimentasi akan memiliki shake (guncangan) yang besar pada saat terjadi gempa namun akan kembali ke bentuk semula dengan cepat juga. Kondisi ini yang memperkuat efek goncangan dari gempa bumi.

\section{Analisa Potensi Area Terdeformasi} Berdasarkan Magnitude Gempa

Gempa bumi yang terjadi pada tanggal 25 Oktober 2010 di Kepulauan Mentawai mempunyai kekuatan 7,8 SR yang ditunjukkan dengan warna bintang merah. Gambar 8 memperlihatkan magnitude gempa mulai dari skala 4 SR pada tahapan coseimic dan postseismic.

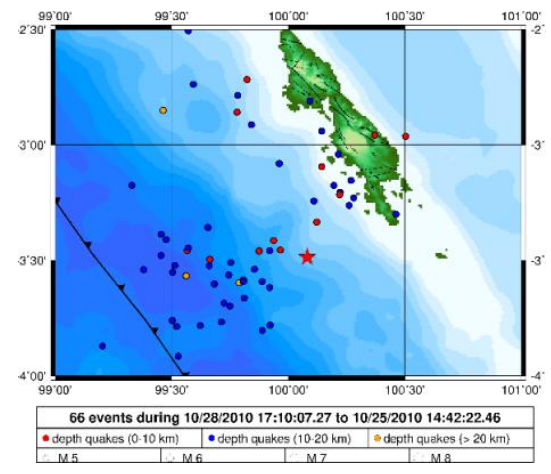

Gambar 8. Plotting Magnitude Gempa (a) 2D dan (b) 3D

Gempa bumi terjadi pada zona awal penunjaman (subduksi) lempeng Indo-Australia terhadap lempeng Eurasia di Samudra India yang dikenal dengan zona megathrust. Hal ini mengindikasikan bahwa gempa yang terjadi di Kepulauan Mentawai akibat aktifitas jalur lempeng tektonik yang ada di bawah kepulauan tersebut. Berdasarkan bentuk morfologi dan posisinya terhadap daerah penunjaman, maka dapat diduga bahwa daerah pantai barat Kepulauan Mentawai merupakan daerah yang memiliki resiko kebencanaan geologi yang tinggi.

6. Validasi Besar Deformasi dari DInSAR dengan Data GPS SuGAr

Pola deformasi pada citra InSAR merupakan deformasi relatif terhadap Line of Sight (LOS). Pola deformasi yang terlihat masih belum terlalu jelas karena beberapa distorsi baik berupa dekorelasi temporal maupun dekorelasi geometri belum sepenuhnya hilang. Pengaruh topografi pada citra hasil pengolahan DInSAR juga belum dapat dihilangkan sepenuhya. Hal tersebut dipengaruhi oleh data DEM yang digunakan. Ketelitian vertikal yang dimiliki oleh DEM hasil SRTM3 adalah $16 \mathrm{~m}$ sehingga penentuan tinggi pada saat proses subtraksi pengaruh topografi masih memiliki kesalahan. Hal tersebut mengakibatkan phase akhir pada phase interferogram masih mengandung sinyal topografi.

Untuk membandingkan displacement yang terjadi di setiap stasiun GPS dengan menggunakan metode DInSAR dan data GPS dalam SuGAr Network ditunjukkan pada Tabel 4.4. Vektor pergeseran SAR dalam 1D sepanjang LOS sistem radar yang terdiri dari komponen 
perpindahan vertikal, easting dan northing. Hal ini dikarenakan keterbatasan informasi data $S A R$ dari perbedaaan sudut pandang (incidence angle) dan orbit di periode waktu yang sama sehingga tidak mungkin untuk menurunkan perpindahan vektor 3D. Hipotesa nol yang digunakan dalam penelitian ini adalah "Pergeseran Data SAR Tidak Dapat Digunakan Sebagai Hasil Pemantauan Besar Deformasi Dibandingkan dengan Pergeseran Tiap Stasiun GPS". Jika level signifikan $(\alpha)$ yang digunakan adalah 0,05 dengan derajat kebebasan $6(n=7)$, maka didapatkan $t$-distributions $\left(t_{\alpha / 2}\right)$ $=t_{0,975,6}=2,45$ (dari tabel student $t$-test) dan hipotesa statistik, hasil uji $t$-test dapat dilihat pada Tabel 1.

Tabel 1. Hasil Uji t-test

\begin{tabular}{|c|c|c|c|c|c|c|}
\hline No & $\begin{array}{l}\text { Nama } \\
\text { Stasiun }\end{array}$ & $\begin{array}{c}\text { Data } \\
\text { GPS/ } \mu \\
(\mathrm{cm}) \\
\end{array}$ & $\begin{array}{c}\text { Data } \\
\mathrm{SAR} / \overline{\mathrm{y}} \\
(\mathrm{cm}) \\
\end{array}$ & $\begin{array}{c}\overline{\mathrm{y}}- \\
\mathrm{t} \alpha / 2 * \mathrm{~S} / \sqrt{ } \\
\mathrm{n}(\mathrm{cm})\end{array}$ & $\begin{array}{c}\bar{y}+ \\
\mathrm{t} \alpha / 2 * \mathrm{~S} / \sqrt{ } \\
\mathrm{n}(\mathrm{cm}) \\
\end{array}$ & $\mathrm{H} 0$ \\
\hline 1 & BSAT & 7,268 & 6,500 & 4,310 & 8,690 & Ditolak \\
\hline 2 & PRKB & 4,352 & 4,500 & 3,218 & 5,782 & Ditolak \\
\hline 3 & SLBU & 5,576 & 7,500 & 5,307 & 9,693 & Ditolak \\
\hline \multirow{2}{*}{\multicolumn{2}{|c|}{$\begin{array}{c}\bar{y}- \\
t \alpha / 2 * S / V n \\
(\mathrm{~cm})\end{array}$}} & $\begin{array}{c}\bar{y}+ \\
t \alpha / 2 * S / V n \\
(\mathrm{~cm})\end{array}$ & HO & & & $\begin{array}{l}\text { Nama } \\
\text { Stasiun }\end{array}$ \\
\hline & & & & $95 \%$ & 2,45 & \\
\hline & $\begin{array}{l}4,310 \\
3,218\end{array}$ & $\begin{array}{l}8,690 \\
5,782\end{array}$ & $\begin{array}{l}\text { Ditolak } \\
\text { Ditolak }\end{array}$ & $99 \%$ & 3,71 & $\begin{array}{l}\text { BSAT } \\
\text { PRKB }\end{array}$ \\
\hline & 5,307 & 9,693 & Ditolak & & & SLBU \\
\hline
\end{tabular}

Berdasarkan Tabel 1. dapat disimpulkan $\mathrm{H}_{0}$ ditolak dan $\mathrm{H}_{\mathrm{a}}$ diterima, dengan kata lain "Pergeseran Data SAR Dapat Digunakan Sebagai Hasil Pemantauan Besar Deformasi Sama Seperti Pergeseran Tiap Stasiun GPS".

\section{PENUTUP}

\section{Kesimpulan}

Berdasarkan hasil penelitian di atas, dapat disimpulkan sebagai berikut :

1. Teknologi SAR cukup efektif untuk melihat besar deformasi dibuktikan dengan hasil pengolahan data GPS dalam SuGAr Network memiliki kecenderungan pola deformasi yang sama dengan hasil yang di dapatkan dari metode DInSAR baik di area yang mengalami uplift atau subsidence.

2. Berdasarkan hasil unwrap menunjukkan bahwa di Kepulauan Mentawai bagian timur terjadi subsidence dan uplift di wilayah barat.
3. Dari pengolahan DInSAR didapatkan besar deformasi terhadap line of sight(LOS) dengan nilai $-20 \mathrm{~cm}$ sampai dengan $20 \mathrm{~cm}$.

4. Hasil validasi pergeseran data $S A R$ menggunakan data GPS dalam SuGAr Network menunjukkan bahwa besar deformasi yang didapatkan dari metode DInSAR dapat digunakan untuk pemantauan deformasi yang dibuktikan dengan hasil uji statistika dengan tingkat kepercayaan 95\% dan derajat kebebasan 6 .

\section{DAFTAR PUSTAKA}

Ghilani,C.D dan P.R.Wolf. 2006. Adjusment Computations Spatial Data Analysis Fourth Edition. Canada: John Wiley \& Sons, Inc

Hanssen, R.F. 2001. Radar Interferometry. Data Interpretation and Error Analysis. Kluwer Academic Publishers. The Netherlands: Delft University of Technology.

Mubyarto, F. 2008. Analisis Pola Deformasi Interseismic Gempa Bengkulu 2007 dari Data GPS Kontinyu SuGAr. Bandung: Teknik Geodesi dan Geomatika, Institut Teknologi Bandung.

Ng, A.H., dkk. 2008. Radar Interferometry for Ground Subsidence Monitoring Using ALOS PALSAR Data. Beijing : The International Archives of the Photogrammetry, Remote Sensing and Spatial Information Sciences. Vol. XXXVII. Part B7.

Sharav, A. 2003. Differential SAR Interferometry for crustal deformation study. The Netherlands : International Institute For Geo-Information Science And Earth Observation Enschede.

Yudhicara, W. K. 2010. "Jejak tsunami 25 Oktober 2010 di Kepulauan Mentawai berdasarkan penelitian kebumian dan wawancara". Jurnal Lingkungan dan Bencana Geologi 1, 3:165-181. 